\title{
Original paper \\ First document on the presence of Iraqi Dirofilaria immitis
}

\author{
Amall hassen atia* and Aleia Y. Yakoob** \\ *Institute of medical technology-mmission of technical educationBaghdad - Iraq \\ **Dept. of parasitology-college of vet. Med.-Baghdad University -Baghdad- Iraq
}

\section{Summary}

Canine dirofilariasis in Iraq was thought not present. This is the first report of dog heartworms in our country. Hearts of 22 dogs from various sites in Kerbala province were examined for Dirofilaria immitis infection. Peripheral blood from dogs with worms in the heart was examined for microfilaria. Adult worms were found in 16 (73\%) hearts. Microfilaria in blood not tackled in the present work. From these finding we hypothesis that heartworm disease is usually present in / or imported from those areas that are endemic for canine dirofilariasis.

Key words: nematode, filarial, Dirofilaria immitis , canine heartworms, Kerbala, Iraq .

$$
\begin{aligned}
& \text { التوثيق الأول لوجود الدايروفيلاريا ايميتس العراقية }
\end{aligned}
$$

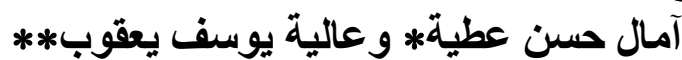

$$
\begin{aligned}
& \text { * المعهد التقني الطبي - بغداد ـالعر اق اقت }
\end{aligned}
$$

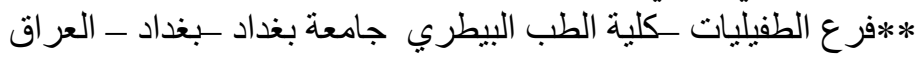

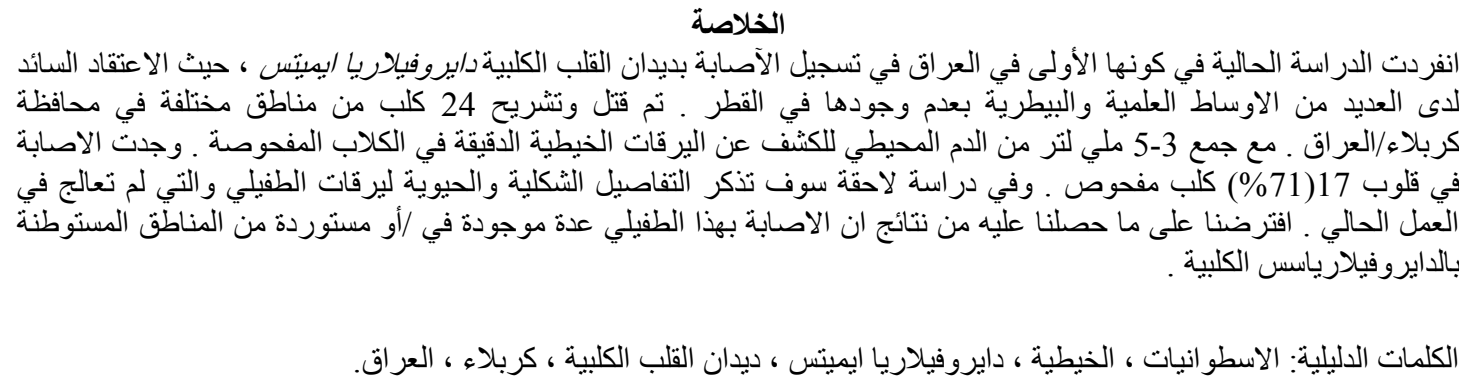

\section{Introduction}

Dirofilaria immitis a mosquito-borne nematode parasite which is widely distributed throughout the world and is most prevalent in the tropical and subtropical zones [ $1 \& 2$ \& . Although dogs and wild canines are considered to be the natural hosts for this parasite, it can infected other species of animals as well as man. Since 1979, heartworms have been known as a zoon sis, and humane are the dead end host [3-5] . The adult worms usually found in the right side of the heart or in the pulmonary arteries, while microfilaria Mfs circulate in the peripheral blood [6] . It is most common important parasite, in heavy infestation ,causing sever cardiopulmonary and even death of some animals [7] .

The taxonomic groups are genus and species Dirofilaria immitis (Leidy, 1856; Railliet and Henry, 1911) of family Onchocercidae of ordre Spirurida of subclass Spiruria of class Secernentea [ 8 ] .

Canine dirofilariasis in Iraq was thought not present. This is the first case of heartworms infection in Iraq to our knowledge.

\section{Materials and Methods}

The hearts of 22 mixed breed dogs ( guarding and herding breed) from both sex , 9 months and over 11 years old were examined for Dirofilaria immitis from various sites of kerbala province /Iraq, were killed and autopsied from last May to mid June 2008 . Hearts and lungs were removed from the thoracic cavity through the diaphragm and abdomen. All chambers of the heart and adjacent vessels were opened and examined for heartworms. Blood samples was drawn in EDTA tubes were examined for Mfs not tackled in the present work. 


\section{Results}

Adult of Dirofilaria immitis were found in 17 of $24(70.83 \%)$ dogs (Table 1). Worms were found in the right and right ventricle of the heart, pulmonary artery, in the middle and lower lobes of the left and right lungs and their pulmonary vessels (Figure 1)

The results of this study show that the rate of Dirofilaria immitis in male were 16 of $17(94.11 \% 0$ while in female the rate of infection in percentage of $5.88 \%$.

Only $8(47 \%)$ dogs harboring adult parasite and Mfs (4 dogs had females worms and one a male) . $9(52.94 \%)$ dogs had worms without Mfs in their blood (4 dogs had only female , 1 dog only a male and four dogs had both sexes).

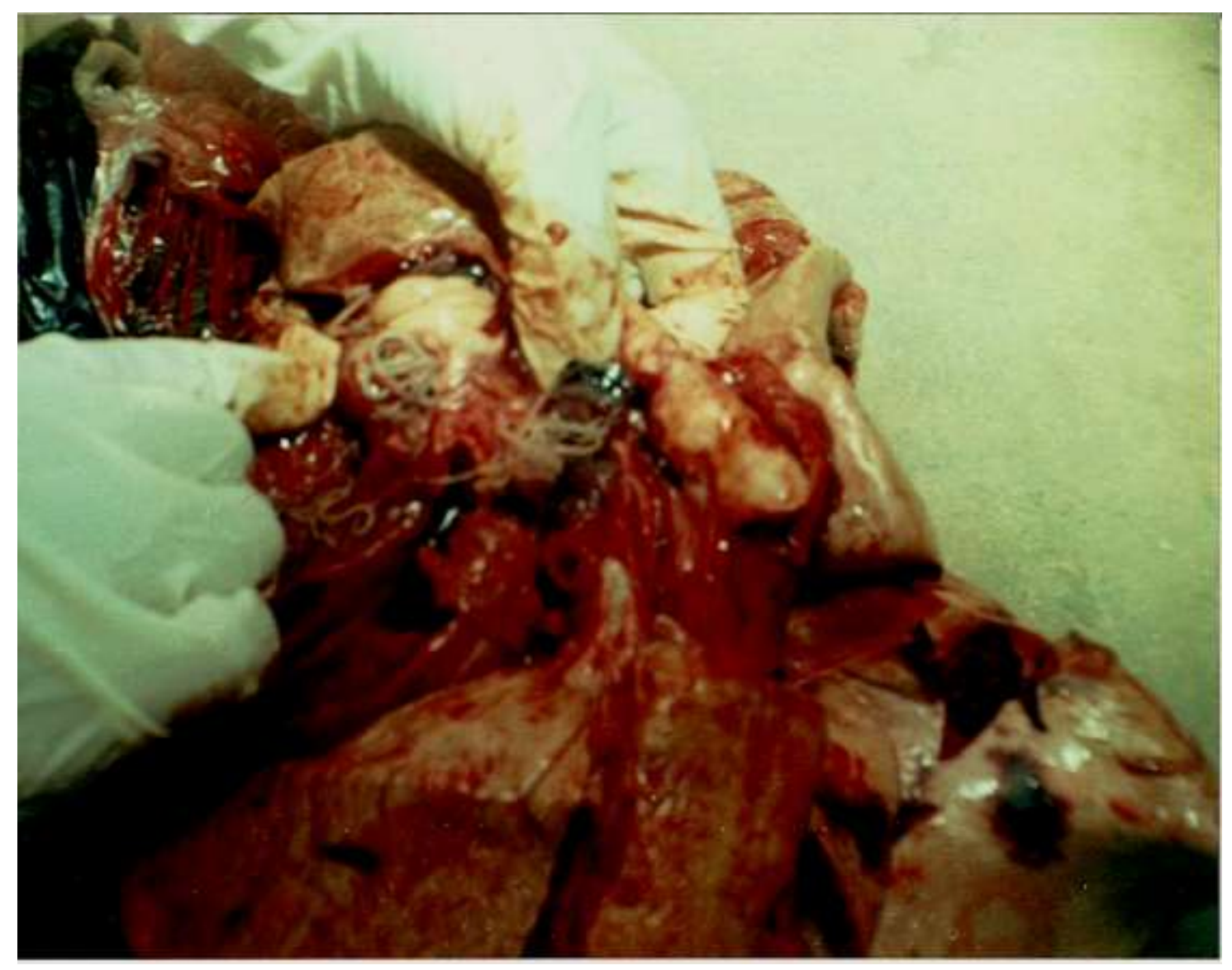

Fig. ( 1 ) Dirofilaria immitis in the lung \& heart from infected dog . 
Iraqi Journal of Veterinary Medicine Vol. 33, No. 1, 2009

Table(1): prevalence of Dirofilaria immitis infection in 24 dogs from kerbala/Iraq

\begin{tabular}{|c|c|c|c|c|c|}
\hline Dog no. & Date & Sex & Microfilaria in blood & Adult worms & $\begin{array}{l}\text { No. of worms in } \\
\text { heart \& lungs }\end{array}$ \\
\hline 1 & 25.5 .08 & M* & Absent & & \\
\hline 2 & $=$ & $\mathbf{F} * *$ & $=$ & & \\
\hline 3 & 26.5.08 & $\mathbf{F}$ & $=$ & & \\
\hline 4 & 27.5 .08 & $\mathbf{F}$ & $=$ & & \\
\hline 5 & $=$ & $\mathbf{M}$ & $=$ & & \\
\hline 6 & 29.5.08 & $\mathbf{M}$ & Present & & \\
\hline 7 & 6.6.08 & $\mathbf{M}$ & $=$ & & \\
\hline 8 & 7.6.08 & $\mathbf{M}$ & $=$ & & \\
\hline 9 & $=$ & $\mathbf{F}$ & Absent & & \\
\hline 10 & $=$ & $\mathbf{M}$ & Present & & \\
\hline 11 & 9.6 .08 & $\mathbf{M}$ & Absent & & \\
\hline 12 & $=$ & $\mathbf{M}$ & $=$ & & \\
\hline 13 & $=$ & $\mathbf{M}$ & $=$ & & \\
\hline 14 & $=$ & $\mathbf{M}$ & $=$ & & \\
\hline 15 & $=$ & $\mathbf{M}$ & $=$ & & \\
\hline 16 & $=$ & $\mathbf{M}$ & Present & & \\
\hline 17 & 10.6 .08 & $\mathbf{M}$ & $=$ & & \\
\hline 18 & $=$ & $\mathbf{F}$ & $=$ & & \\
\hline 19 & $=$ & $\mathbf{M}$ & Absent & & \\
\hline 20 & 12.6.08 & $\mathbf{M}$ & $=$ & & \\
\hline 21 & $=$ & $\mathbf{F}$ & $=$ & & \\
\hline 22 & $=$ & $\mathbf{M}$ & Present & & \\
\hline 23 & $=$ & $\mathbf{M}$ & Absent & & \\
\hline 24 & $=$ & $\mathbf{M}$ & $=$ & & \\
\hline
\end{tabular}

\section{Discussion}

Canine dirofilariasis in Iraq was not reported and was thought not present. We Surprise with the high prevalence of infection $(72.72 \%)$. We hypothesized that these areas are enzootic foci for canine dirofilariasis . However this is first study with Dirofilaria immitis infection in dogs in Iraq particular in kerbala province. Heartworm more prevalent in areas study because : of the abundance of mosquitoes . The rate of infection in mosquito generally correlates with the number of Mfs in patients, whether humans or animals [9].Areas of study are forested and serve as ideal habitats for the development of mosquitoes [10]. The more male dogs than female dogs were infected may be related to the roaming of male dogs rather than to a susceptibility differences due to size, sex or hair length [11]. Infection primarily related to exposure to infected mosquitoes and not to any susceptibility differences [12].

In this study, the Mfs in dogs infected with D.immitis was absent, are probably related to the occult form of the disease, the main reason was absence of one sex[13], or that the rate of infectivity for $D$. immtis in mosquitoes is lower [9[. The presence of worms from single sex in heart with Mfs in peripheral blood may be due to death worm of opposite sex [13]. The location, low socio-economic conditions and urbanization of these areas contribute to the high density of vectors [10] and thus the presence of this filarial infection in many parts of the province .Finally, from these finding we hypothesized that heartworm disease is usually present in/or imported from those areas that are endemic for canine dirofilariasis. 


\section{Reference}

1. Otto GF and Jackson RF (1975) Heartworm disease. In Textbook of Veterinary Internal Medicine. Saunders company, Philadelphia; 1014-1038 .

2. Annual report(2001) prevalence of heartworm in owned dogs in Grenada, West Indies .

3. OMS-Organizacion Mundial de la Salud (1979) Zoonsis Parasitarias . In :Labarth, Almosny N, Guerror J AND Duque-Araujo AN . Description of the canine dirofilariasis in the state of Rio de Janeiro, Brazil. Memorias do Instituto Oswaldo Cruz. 92 (1) 47-51 .

4. Genchi C, Simon F and Kramer L (2005) Dirofilariasis in humans : IS It a real Zoon tic concern ? 30th World Congress the World of the Small Animal Veterinary Association.

5. Atkins C(2005) Heartworm disease in dogs: An update . Proceeding of the 30th World Congress the World of the Small Animal Veterinary Association Retrieved on 2007.

6. JAOSE RM de Campos, Carmen SVB, Luiz TBF, Angelo F, Helio M, Joao VBF and Fabio BJ (1997) Human pulmonary dirofilariasis : Analysis of 24 cases from Sao Paulo, Brazil. Chest. 112; 729-733.

7. Lindsey JR (19620 Diagnosis of filarial infection $\mathrm{n}$ dogs. II Confirmation of microfilarial identification . Journal parasitology 48; 321-326.

8. Soulsby EJ (1982) Helmithes, arthropods and protozoa of domesticated animals Philadelphia, London, 293.

9. Cancrini G, Magi M, Gabrielli S, Arispici M, Tolari F, Dell Omodarme M, Prati MC (2006) Nature vectors of dirofilariasis in rural and urban areas of the Tuscan region, central Italy . Journal of Medical Entomology , 43(3) 574-579 .

10. Alves LC de Almeida Silva LV, Faustino MA (1999) Survey of canine heartworm in the city of Recife, Pernambuco, Brazil. Memorias do Instituto Oswaldo Cruz. 94(5)587-90 .

11. Robert HS, Paul CS, JP Dubey (1977) Prevalence of Dirofilaria immitis infection in dogs from a human shelter in Ohio. Journal American of Veterinary Medicine Association 170(7)720-721.

12. Robert WT. Dirofilariasis .Update 2008. www.emedicine.com .

13. Matic SE and Herrtage ME(1987) Diagnosis and treatment of occult dirofilariasis in an imported dog. The Journal of Small Animals Practice 28(3)183-196. 